\title{
Squamous papilloma: an unusual esophageal entity
}
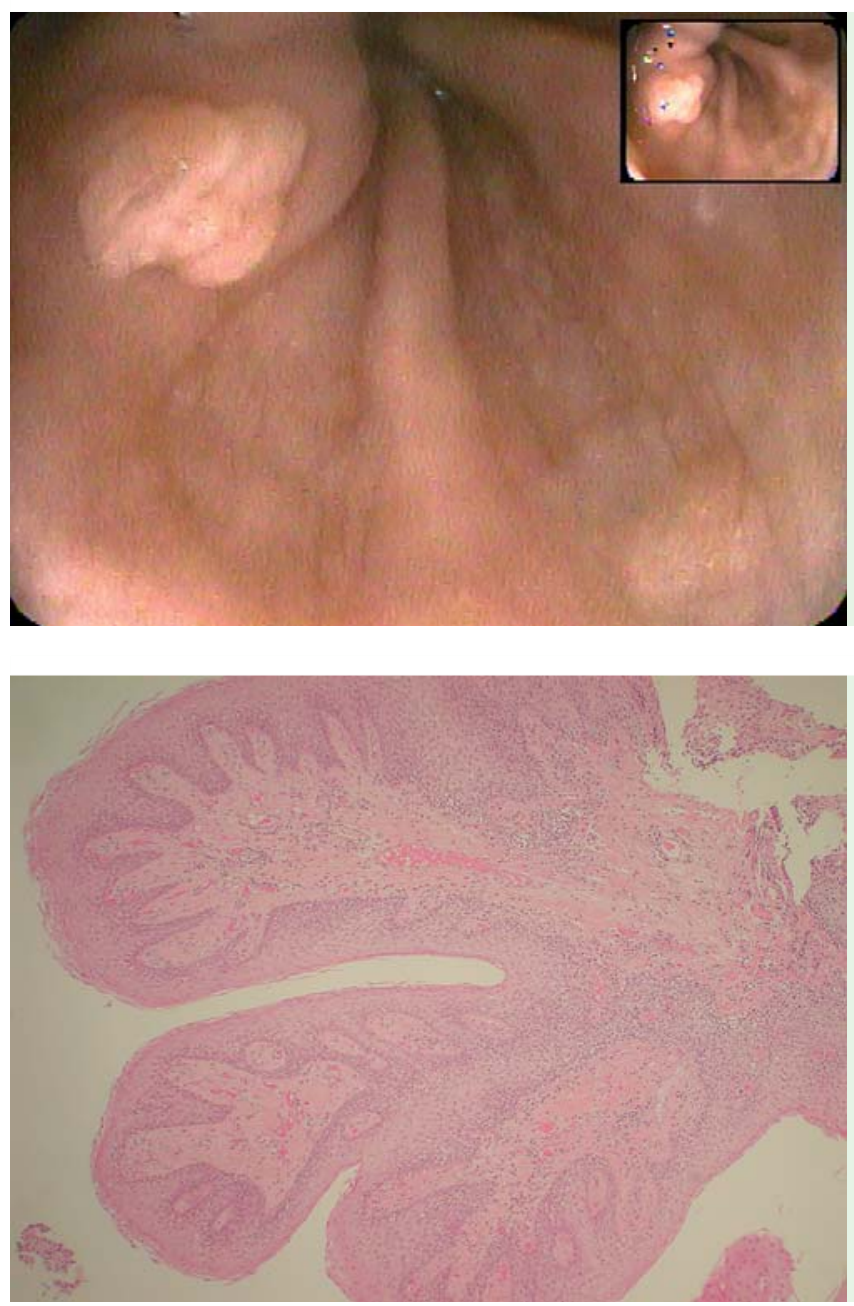

Fig. 1 Wart-like lesion from patient 1 on endoscopy.

Fig. 3 Histopathological findings showing the typical branching core of lamina propria producing frond-like structures that are covered by squamous epithelium (Hematoxylin and eosin; magnification, $\times 40$ ).
We describe a case series of two patients who underwent esophagogastroduodenoscopy (EGD) for different indications.

The first case is a 61-year-old man who presented with symptoms of intermittent dysphagia to solids for 2 months. EGD showed a $1.5-\mathrm{cm}$ exophytic mass in the distal esophagus ( Fig. 1). The lesion was removed with jumbo biopsy forceps. Pathology was consistent with squamous cell papilloma of the esophagus. Special stain was negative for human papilloma virus DNA in the lesion. Follow-up EGD was performed 3 months later, which showed normal-appearing mucosa. The patient improved symptomatically with no further complaints of dysphagia.
The second case is a 56-year-old man referred for EGD for abdominal pain and nausea. He did not report dysphagia. He had a past history of tobacco and alcohol use. EGD showed a nodular lesion at $30 \mathrm{~cm}$ from the incisors ( $\bullet$ Fig. 2), which was removed. Pathology showed squamous papilloma without dysplasia.

Squamous papilloma of the esophagus is a rare benign lesion of the esophagus. The prevalence ranges from $0.01 \%$ to $0.45 \%$ [1]. Squamous papilloma of the esophagus is usually asymptomatic and rarely causes dysphagia. This entity presents as a wartlike lesion, most commonly in the middle and distal esophagus, and can be removed endoscopically [2].

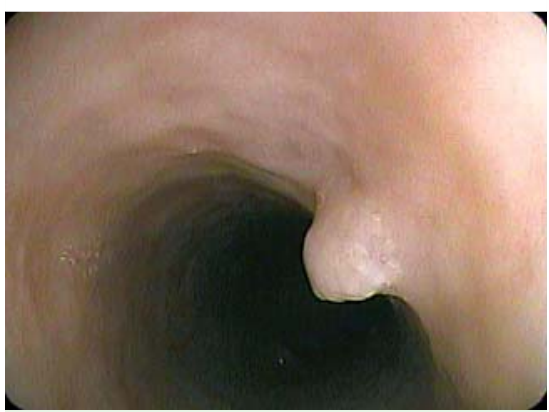

Fig. 2 Endoscopic image of lesion in patient 2.

The underlying etiology is unclear, but chronic reflux disease, mucosal trauma, and human papillomavirus (HPV) infection have been implicated, although most lesions are found to be HPV negative [2,3]. Histologically there are three different forms. The most common form has a branching core of lamina propria producing fronds that are covered by squamous epithelium ( Fig.3). Occasionally the squamous epithelium has koilocytotic changes with crinkled nuclei surrounded by clear cytoplasmic halos resembling the squamous cells of condylomas [2].

The malignant potential of the lesion is unknown, and no guidelines exist regarding follow-up of these lesions. Long-term follow-up studies have suggested removing the lesion endoscopically. Recurrence is uncommon.

\section{Acknowledgement \\ $\nabla$}

The authors would like to thank the following people from Veterans Affairs Medical Center for assistance with the pathology slides: Dr Jianhua Wu and Dr Elizabeth Jensen from the Department of Pathology, and Mr Sidney Crandall from Medical Imaging.

Endoscopy_UCTN_Code_CCL_1AB_2AC_3AB

Competing interests: None 


\section{P. Kanth ${ }^{1}$, M. F. Go ${ }^{2}$}

1 Division of Gastroenterology, University of Utah Health Center, Salt Lake City, Utah, USA

2 Division of Gastroenterology, Veterans Affairs Medical Center, Salt Lake City, Utah, USA

\section{References}

1 Takeshita K, Murata S, Mitsufuji S et al. Clinicopathological characteristics of esophageal squamous papillomas in Japanese patients - with comparison of findings from Western countries. Acta Histochem Cytochem 2006; 39: 3-30

2 Lewin KJ, Appelman HD. Tumors of the esophagus \& stomach: atlas of tumor pathology. 3rd Series, Vol. 18. American Registry of Pathology. Washington, DC: Armed forced Institute of Pathology; 1995: 31 - 32

3 Odze R, Antonioli D, Shocket D et al. Esophageal squamous papillomas: a clinicopathological study of 38 lesions and analysis for human papillomavirus by the polymerase chain reaction. Am J Surg Pathol 1993; 17: $803-812$

\section{Bibliography}

DOI $10.1055 / \mathrm{s}-0030-1257039$

Endoscopy 2011; 43: E405 - E406

(c) Georg Thieme Verlag KG Stuttgart · New York . ISSN 0013-726X

\section{Corresponding author}

\section{P. Kanth, MBBS}

Division of Gastroenterology

University of Utah Health Center

30 North 1900 East

4R118 SOM

Salt Lake City

Utah 84132

USA

Fax: +1-801-581-7476

kanth2006@yahoo.com 